\title{
Spatial and Temporal Variations in the Rainy Season Onset over the Qinghai-Tibet Plateau
}

\author{
Yuekai Hu ${ }^{1,2} \mathbb{D}^{\mathbb{D}}$, Junfeng $\mathrm{Xu}{ }^{1, * \mathbb{C}}$, Yuxin Huang ${ }^{1}$, Yinying Zhou ${ }^{1}$, Yuwen Pang ${ }^{1}$, Zhou Shi ${ }^{3} \mathbb{C}$ \\ and Xiaojun Chen ${ }^{1}$ \\ 1 Institute of Remote Sensing and Earth Science, College of Science, Hangzhou Normal University, \\ Hangzhou 311132, China; yuekaihu0108@gmail.com (Y.H.); huangyuxin_96@163.com (Y.H.); \\ zyy029681@gmail.com (Y.Z.); tzpangyuwen@gmail.com (Y.P.); chenxiaojun721@gmail.com (X.C.) \\ 2 State Key Laboratory of Estuarine and Coastal Research, East China Normal University, Shanghai 200062, \\ China \\ 3 Institute of Agricultural Remote Sensing and Information Technology Application, College of Environmental \\ and Resource Sciences, Zhejiang University, Hangzhou 310058, China; shizhou@zju.edu.cn \\ * Correspondence: xjf11@zju.edu.cn
}

Received: 23 July 2019; Accepted: 18 September 2019; Published: 20 September 2019

\begin{abstract}
Precipitation on the Qinghai-Tibet Plateau (TP) in southwestern China is subject to interactions between the complex and variable terrain and the sensitive climate. The regional climate is mainly affected by three circulations: westerlies, the South Asian monsoon, and the East Asian monsoon. Spatial and temporal variations in the rainy season onset were characterised based on daily precipitation from 106 meteorological stations on the TP from 1971 to 2015. Using the Theil-Sen Median trend analysis, Mann-Kendall test and mutation detection, the characteristics and reasons for the variations during the rainy season over the plateau over the past 45 years were investigated. The following results were obtained from the analysis: (1) There were obvious regional differences in the rainy season onset over the TP, and the rainy season began on the southeastern plateau and moved northwestward. (2) The TP rainy season underwent a significant mutation in approximately 1997, and following this mutation, the area affected by the delayed rainy season increased. (3) Against the background of global warming, the rainy season trend over the TP was advanced; however, there were still several multiple contiguous concentrated areas on the plateau. (4) Before the rainy season mutation, there were two centres of delayed precipitation on the plateau, which existed primarily due to their location at the end of the plateau water vapour transport channel. After the mutation, the number of delayed precipitation centres on the plateau increased to three and presented a spatially expanding trend, which may be related to the weakening trend in atmospheric circulation.
\end{abstract}

Keywords: onset of the rainy season; nonparametric test; atmospheric circulation; mutation analysis; Qinghai-Tibetan Plateau

\section{Introduction}

Precipitation is a key part of the global atmospheric and hydrological cycles and an important factor that affects the distribution of water resources [1]. Climate warming has accelerated the water cycle by speeding the processes of precipitation, evapotranspiration, and surface runoff and has, thereby, changed the spatial and temporal distributions of water resources, which widely impact the distribution of freshwater resources and the stability of natural ecosystems [2,3]. Subtle changes in precipitation have profound effects on plateau ecosystems, energy cycles, agricultural production, food security, and so on [4-7]. With global warming, the temperatures of both continents and oceans have increased; however, the temperature has increased more slowly in the ocean due to its specific heat, reducing 
the sea-land thermal gradient, which has changed the characteristics of atmospheric circulation and caused variations in the timing and intensity of precipitation events in the region [1], [8-12].

As the "third pole" of the world, the unique ecological geography unit of the Qinghai-Tibet Plateau (TP) has been extensively studied in the climate response field, and the sensitivity of the climate of the TP is well documented. Thus, this plateau has been called the "driver" and "amplifier" of climate change [13-15]. Currently, precipitation characteristics, such as seasonal precipitation, precipitation intensity, and extreme precipitation changes on the plateau have been widely studied by researchers $[16,17]$. The rainy season is the most concentrated period of precipitation during the year on the TP, and the precipitation during this season can reach $90 \%$ of the annual total precipitation [18]. The onset of the rainy season serves as a signal that the plateau climate has changed from dry to wet. The onset of the rainy season is a direct reflection of the modal changes in atmospheric circulation. Studying the spatial and temporal changes in the rainy season onset plays an important role in informing agricultural and water security planning.

The climate of the TP (especially precipitation) is affected by a combination of the South Asian monsoon, westerlies, and the East Asian monsoon [19,20], and subtle changes in atmospheric circulation intensity can cause significant interannual variations in the rainy season onset over the TP. Several investigations have indicated a clear trend in the intensities of the westerlies and monsoon circulation. The TP climate tends towards warm and humid [11,21]. In the context of global climate and circulation changes, the temporal and spatial trends of the rainy season onset over the TP are still unknown. Therefore, in the present study, the temporal and spatial variation characteristics of the rainy season onset over the Tibetan Plateau were investigated, and the results may reveal the variation characteristics in the monsoon circulation system and shed light on the potential impacts of climate change on the global water cycle, which is also meaningful for environmental ecological risk assessments.

The daily precipitation data from 106 meteorological stations from 1971 to 2015 were analysed (Figure 1). Based on GIS spatial analysis, the Theil-Sen Median analysis method combined with the Mann-Kendall test was used to study the relationship between atmospheric circulation changes and the onset of the rainy season on the plateau against a global warming background. The findings can provide a reference for understanding the characteristics of the global water cycle and inform planning to avoid ecological risks.

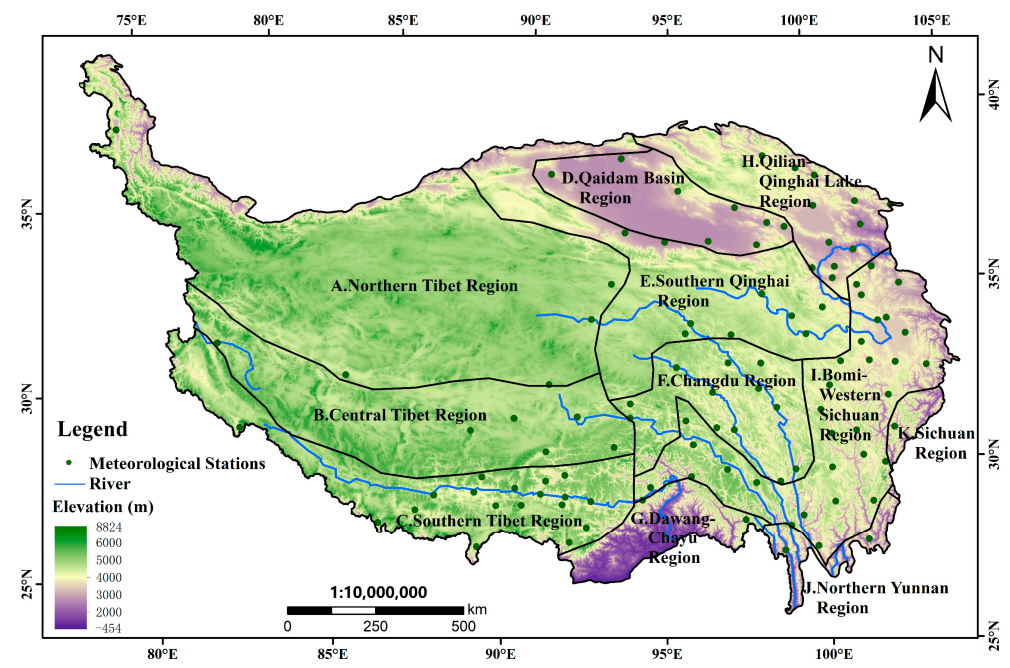

Figure 1. Partitioned regions and meteorological stations over the Qinghai-Tibet Plateau (TP). 


\section{Materials and Methods}

\subsection{Study Area and the Partitioned Regions}

The Qinghai-Tibet Plateau (TP), with an area of 2.5 million $\mathrm{km}^{2}$, lies in southwestern China $\left(73^{\circ} \mathrm{E}-105^{\circ} \mathrm{E}, 25^{\circ} \mathrm{N}-40^{\circ} \mathrm{N}\right)$. The $\mathrm{TP}$ is the highest-altitude region in the world. The terrain of the plateau is complex, and the climate over the plateau has obvious regional characteristics. In this paper, the study area covers Tibet in Qinghai Province and the counties of Sichuan, Yunnan, Xinjiang, and Gansu. The water vapour transport on the TP is mainly derived from three major water vapour channels [20]. The first is located in the middle of the Himalayas in the southwestern part of the TP, the second is in the Brahmaputra River valley in the southeastern part of the TP, and the third is in the Tarim Basin and Qaidam Basin in the northern part of the TP. The water vapour flux of the water vapour channel on the southern TP is mainly affected by the Indian summer monsoon. The water vapour flux of the northern water vapour channel is affected by westerlies. The atmospheric precipitation from the southeast water vapour channel of the plateau is obviously greater than that of the other channels, and there are three high-precipitation centres, which are located in the southwestern, southeastern, and southern parts of the TP [22]. There are obvious spatial and temporal differences in the plateau precipitation. In terms of time, there are obvious dry and wet seasons on the plateau, with precipitation mainly concentrated in the rainy season. In terms of space, the TP precipitation gradually decreases from southwest to northeast. On the western Sichuan Plateau, on the Qinghai Plateau, and south of Bayan Kala Mountain, the annual precipitation is greater than $400 \mathrm{~mm}$, and this area is humid and semihumid. In contrast, the annual precipitation is less than $400 \mathrm{~mm}$ in the western and northern parts of the plateau, which are arid and semiarid regions.

As mentioned above, there are regional differences in precipitation over the plateau. In this paper, based on the climate division of the Chinese Academy of Sciences and by combining the topography, atmospheric circulation, watershed division, and regional precipitation on the plateau, we divided the plateau into 11 regions (Figure 1) to better understand the regional rainy season onset and trend over the TP (A. Northern Tibet, NT; B. Central Tibet, CT; C. Southern Tibet, ST; D. Qaidam Basin, QB; E. Southern Qinghai, SQ; F. Changdu, CD; G. Dawang-Chayu, DC; H. Qilian-Qinghai Lake, QQ; I. Bomi-Western Sichuan, BW; J. Northern Yunnan, NY; K. Sichuan, SC).

\subsection{Datasets}

The ground observations of 106 meteorological stations covering the TP were obtained from the National Meteorological Information Center of China [23]. In the time series, daily precipitation data with strict quality control from 1971 to 2015 (45 years) were selected to ensure the integrity of the datasets and the accuracy of the research results. The datasets were processed in a standard manner to eliminate invalid and erroneous data. We rearranged the original data according to the year and site. Suspicious data were compared to the missing value for quality control, and the missing data accounted for fewer than 5 parts per million, too low to influence the research results.

Shuttle Radar Topography Mission Digital Elevation Model (SRTM DEM) data was obtained from the United States Geological Survey (USGS) website, and the data has a spatial resolution of $30 \mathrm{~m}$ [24].

\subsection{Method}

\subsubsection{Determining the Rainy Season Onset}

The onset of the rainy season was determined according to the relative precipitation coefficient model $[25,26]$. The formula is shown as follows:

$$
\mathrm{C}_{\mathrm{n}}=\frac{\mathrm{A}_{\mathrm{n}}}{\mathrm{A}}
$$


where $A_{n}$ is the average precipitation of day $n, A$ is the average annual precipitation of the meteorological station, and $C_{n}$ is the relative precipitation coefficient of day $n$. Generally, the precipitation coefficient is related to the local annual precipitation [26]. To determine the onset of the rainy season, we need to calculate the 5-day, 10-day, and 15-day relative precipitation coefficients. The relative precipitation coefficient was set as 1.5 to avoid the impact of extreme precipitation on the results.

Thus, the criteria for the rainy season onset are as follows: After a moderate rain day (i.e., daily precipitation greater than $5.0 \mathrm{~mm}$ ), the three indicators $C_{5}, C_{10}$, and $C_{15}$ for a relative precipitation coefficient are simultaneously greater than 1.5; that is, this rainy day can be regarded as the rainy season onset.

\subsubsection{Theil-Sen Median Trend Analysis}

The average annual precipitation clearly differed among the partitioned regions of the TP, and the frequency of extreme precipitation (precipitation events greater than the 95th percentile) on the plateau has increased over the past 50 years [17,27]. The Qaidam Basin and its surrounding area, which is between the Kunlun Mountains and the Qilian Mountains, is a typical arid and semiarid region. The annual average precipitation was less than $400 \mathrm{~mm}$, and a slight change in precipitation may affect the determination of the rainy season onset. The Theil-Sen Median analysis is a nonparametric trend analysis method that is less susceptible to extreme values and is more robust than a traditional parametric analysis [28]. The slope of the rainy season onset was calculated by the following formula:

$$
\mathrm{S}_{\mathrm{ONSET}}=\operatorname{Median}\left(\frac{\mathrm{ONSET}_{\mathrm{j}}-\mathrm{ONSET}_{\mathrm{i}}}{\mathrm{j}-\mathrm{i}}\right), 1971 \leq \mathrm{i} \leq \mathrm{j} \leq 2015,
$$

where $i$ and $j$ represent the observation year, $\mathrm{ONSET}_{\mathrm{i}}$ and $\mathrm{ONSET}_{\mathrm{j}}$ represent the rainy season onset (Julian Day) for the corresponding year from 1971 to 2015, and $\mathrm{S}_{\text {ONSET }}$ represents the median value of the slope of any two years in $n$ years (a total of $C_{n}^{2}$ sets of data). If $S_{\text {ONSET }}$ was less than 0 , the trend of the rainy season onset was delayed; if $S_{\text {ONSET }}$ was equal to 0 , the trend of the rainy season onset had not changed at the corresponding temporal scale; if SONSET was greater than 0 , the trend of the rainy season onset was advanced. In practice, this value of $S_{\text {ONSET }}$ is usually magnified by 10 -fold, which is called the ten-year rate of change and is in units of $\mathrm{d} / 10 \mathrm{a}$.

\subsubsection{Mann-Kendall Test}

The Mann-Kendall (MK) test is a nonparametric statistical method [29,30]. The MK test is a time series method that is commonly used in meteorology and hydrology; this method has the advantages of not being affected by sample values, distribution types, and so on [31-33]. When the MK method is used to obtain a significant determinant of the change trend in the rainy season onset, the rainy season onset of the long-term sequence can be regarded as a set of independent sample data. When $n$ is greater than 8 , the standardised statistical quantity $\mathrm{Z}$ obeys the normal distribution. The calculation is as follows:

$$
Z=\left\{\begin{array}{c}
\frac{\mathrm{S}-1}{\sqrt{\operatorname{var}(\mathrm{S})},}, \mathrm{S}>0 \\
0, \mathrm{~S}=0 \\
\frac{\mathrm{S}+1}{\sqrt{\operatorname{var}(\mathrm{S})},} \mathrm{S}<0
\end{array}\right.
$$

In Equation (3), $\mathrm{S}$ is calculated with Equation (4), and the variance var(s) is computed with Equation (5).

$$
\begin{gathered}
S=\sum_{i=1}^{n-1} \sum_{j=i+1}^{n} \operatorname{sign}\left(\mathrm{ONSET}_{j}-\text { ONSET }_{i}\right), \\
\operatorname{var}(S)=\frac{1}{18}\left[n(n-1)(2 n+5)-\sum_{p=1}^{q}\left(t_{p}-1\right)\left(2 t_{p}+5\right)\right],
\end{gathered}
$$




$$
\operatorname{sign}\left(\mathrm{ONSET}_{\mathrm{j}}-\mathrm{ONSET}_{\mathrm{i}}\right)=\left\{\begin{array}{c}
\operatorname{1ONSET}_{\mathrm{j}}-\mathrm{ONSET}_{\mathrm{i}}>0 \\
\mathrm{OONSET}_{\mathrm{j}}-\mathrm{ONSET}_{\mathrm{i}}=0 \\
-1 \mathrm{ONSET}_{\mathrm{j}}-\mathrm{ONSET}_{\mathrm{i}}<0
\end{array} .\right.
$$

In Equation (6), the sign is a function symbol, q represents the number of ties (repeated data) in the current time series, $p$ represents a tie, and $t_{p}$ is the width of a tie (the number of times the same data appears). For a given $\alpha$, if $|Z| \geq Z_{1-\alpha / 2}$, there is a significant trend in the rainy season onset. In this paper, the confidence level $\alpha$ is taken as 0.1 , and the corresponding $|Z|$ is 1.645 .

\subsubsection{Moving $t$-test}

Due to the mutation detection limitations of the MK test [33-35], a moving $t$-test was applied to test the time point of precipitation mutation over the TP, and the formula is shown as follows:

$$
\begin{gathered}
\mathrm{q}=\left(\overline{\mathrm{y}_{1}}-\overline{\mathrm{y}_{2}}\right) /\left(\mathrm{s} * \sqrt{\frac{1}{\mathrm{n}_{1}}+\frac{1}{\mathrm{n}_{2}}}\right), \\
\mathrm{s}=\sqrt{\left(\mathrm{n}_{1} * \mathrm{~s}_{1}^{2}+\mathrm{n}_{2} * \mathrm{~s}_{2}{ }^{2}\right) /\left(\mathrm{n}_{1}+\mathrm{n}_{2}-2\right),}
\end{gathered}
$$

During the inspection process, a reference time point needs to be set. The two subsequences before and after this time are $y_{1}$ and $y_{2}$, respectively. The sample sizes of the two subsequences are $n_{1}$ and $\mathrm{n}_{2}$, and the variances in the two subsequences are $\mathrm{s}_{1}{ }^{2}$ and $\mathrm{s}_{2}{ }^{2}$. In addition, $\mathrm{q}$ is the statistic that follows the $t$ distribution of degrees of freedom $v=n_{1}+n_{2}-2$. In this study, the sliding method was used, and the statistical array $q_{i}$ can be obtained by sequentially recursing the reference point. For a given level of significance $\alpha=0.05$, there was a corresponding $q_{\alpha}$. If $\left|q_{i}\right|$ is greater than $\left|q_{\alpha}\right|$, the set reference time point can be regarded as a mutation point.

\subsubsection{Cumulative Anomaly Model}

For precipitation data, the cumulative anomaly model can be used as a detector for the mutation in the time series. For the cumulative anomaly value at a certain time $t$ in the sequence, the curve formed by time is the cumulative anomaly curve. The formula is shown as follows:

$$
D_{P_{i}}=\sum_{i=1971}^{i=t}\left(P_{i}-\bar{P}\right)(1971<t \leq 2015)
$$

In Equation (9), $P_{i}$ represents the annual precipitation in year $i$ and $\bar{P}$ represents the mean annual precipitation from 1971 to 2015 . The cumulative anomaly curve reflects the change in annual precipitation. The rising part is the precipitation increasing stage, and the falling part is the precipitation decreasing stage. The turning point of the curve can be regarded as the mutation year of precipitation.

\section{Results}

\subsection{Spatial Distribution Characteristics of the Rainy Season Onset over the TP}

The mean rainy season onset (1971-2015) of each meteorological station was calculated based on the daily precipitation data (Table 1). The average rainy season onset at most stations on the plateau was in the range of $145 \pm 25$ days, i.e., the onset was between late May and mid-June. At this time, it was summer on the TP, and the precipitation was related to the Indian summer monsoon. During this period, the plateau precipitation was mainly obtained through the water vapour channel of the Brahmaputra River in the southeastern plateau, which originated from the Indian Ocean $[6,36]$. 
Table 1. List of meteorological stations in the region and the annual average rainy season onset (Julian Day).

\begin{tabular}{|c|c|c|c|c|c|c|c|}
\hline Station (Region) & Onset & Station (Region) & Onset & $\begin{array}{l}\text { Station } \\
\text { (Region) }\end{array}$ & Onset & $\begin{array}{l}\text { Station } \\
\text { (Region) }\end{array}$ & Onset \\
\hline Tashikuergan (A) & 149 & Pali (C) & 135 & Changdu (F) & 150 & Ganzi (I) & 132 \\
\hline Wudaoliang (A) & 156 & Jiacha (C) & 150 & Dege (F) & 146 & Banma (I) & 134 \\
\hline Anduo (A) & 158 & Lenghu (D) & 194 & Mangkang (F) & 150 & Daofu (I) & 139 \\
\hline Tuotuohe (A) & 162 & Dachaidan (D) & 140 & Milin $(\mathrm{G})$ & 124 & $\mathrm{Aba}(\mathrm{I})$ & 133 \\
\hline Shiquanhe (B) & 194 & Delingha (D) & 130 & Chayu (G) & 76 & Maerkang (I) & 127 \\
\hline Naqu (B) & 154 & Wulan (D) & 136 & Yeniugou (H) & 152 & Songpan (I) & 114 \\
\hline Shenzha (B) & 169 & Dulan (D) & 120 & Qilian (H) & 144 & Luolong (I) & 127 \\
\hline Dangxiong (B) & 155 & Chaka (D) & 140 & Gangcha $(\mathrm{H})$ & 149 & Bomi (I) & 86 \\
\hline Jiali (B) & 144 & Xiaozaohuo (E) & 187 & Menyuan (H) & 134 & Basu (I) & 130 \\
\hline Pulan (C) & 78 & Geermu (E) & 171 & Wushaoling $(\mathrm{H})$ & 147 & Xinlong (I) & 140 \\
\hline Lazi (C) & 164 & Zhiduo (E) & 157 & Qiabuqia (H) & 130 & Litang (I) & 147 \\
\hline Lasa $(\mathrm{C})$ & 156 & Guoluo (E) & 136 & Tongde $(\mathrm{H})$ & 138 & Kangding (I) & 118 \\
\hline Mozhugongka (C) & 149 & Dari (E) & 141 & Zeku (I) & 144 & Derong (I) & 163 \\
\hline Qiongjie (C) & 157 & Zaduo (F) & 146 & Tongren (I) & 124 & Deqin (I) & 103 \\
\hline Zedang $(\mathrm{C})$ & 158 & Yushu (F) & 142 & Henan (I) & 134 & Jiulong (I) & 134 \\
\hline Nielamu (C) & 73 & Shiqu (F) & 144 & Jiuzhi (I) & 134 & Zhongdian (I) & 126 \\
\hline Dingri (C) & 177 & Suoxian (F) & 146 & Maqu (I) & 140 & Xiaojin (J) & 118 \\
\hline Jiangzi (C) & 163 & Biru (F) & 144 & Langmusi (I) & 140 & Muli (K) & 148 \\
\hline Langkazi (C) & 163 & Nangqian (F) & 143 & Ruoergai (I) & 134 & Gongshan (K) & 62 \\
\hline Cuona (C) & 111 & Leiwuqi (F) & 144 & Hezuo (I) & 130 & & \\
\hline Longzi (C) & 160 & Shiquluoxu (F) & 141 & Dingqing (I) & 148 & & \\
\hline
\end{tabular}

An onset date contour was generated using the spatial interpolation model in ArcGIS 10.5 (Figure 2). The onset of the rainy season of the TP increased from south to north and from east to west with the advance of the rain belt, and the overall pattern showed a trend from southeast to the central and western regions.

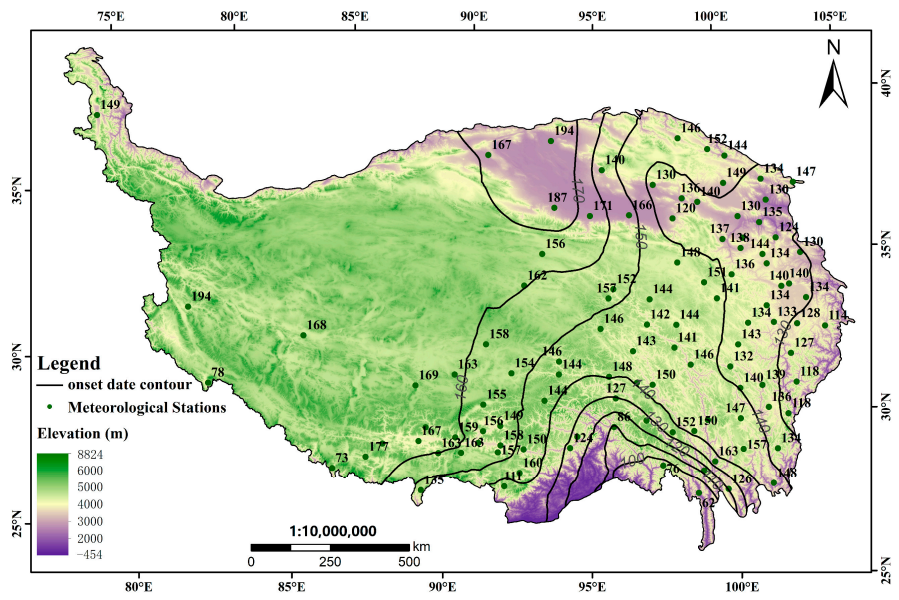

Figure 2. Spatial distribution of rainy season onset on the TP (1971-2015). (Stations are sparse in the western TP; therefore, the five stations in the west were not part of the contour interpolation calculations.).

The annual average rainy season onset on the plateau and its surrounding areas first appeared at the Gongshan station in Yunnan (the 62nd day) on the west side of the Hengduan Mountains. The last appeared at the Shiquanhe Station on the Ali Plateau in the western TP (the 194th day) and the Lenghu station (the 194th day) on the northwestern edge of the northern Qaidam Basin, a difference of 132 days. The rainy season started in March based on six stations (Gongshan, Weixi, Nielamu, 
Chayu, Pulan, and Bomi). Among these stations, four are located in the Hengduan Mountain region. The precipitation in this area is controlled by winter westerlies and the Indian summer monsoon, and the annual precipitation has a bimodal pattern, i.e., the region has a peak of precipitation in spring and a second peak in summer, and the precipitation is more abundant in summer [37]. The southwestern part of the Hengduan Mountains is a vast plains region. The low-altitude westerlies in the early spring are blocked by the TP after passing through the plains, which causes an early precipitation centre at the end of February and beginning of March in the area west of the Hengduan Mountain region. The rainy season onset over the plateau is closely related to the terrain and mountain ranges. The main mountain ranges in the northern part of the TP are east-west oriented, which provides the main water vapour channel via the midlatitude westerlies. The southern part of the TP is mainly the valley plain of the Brahmaputra River basin, which is located between the Gangdese Mountains and the Himalayas and is mainly influenced by the Indian summer monsoon. The Hengduan Mountains are in the southeastern part of the TP, and the main mountain ranges are north-south, which provides a south-north water vapour channel for the Indian summer monsoon [37].

The existence of the Brahmaputra River valley provides a favourable water vapour transport channel for the Indian summer monsoon. The monsoon carries sufficient water vapour upstream along the valley, making the rainy season onset in the middle and lower reaches of the river begin earlier than in the upper reaches of the river. The coastal areas of the river valley are extremely obvious, e.g., the rainy season onsets in Jiacha (the 150th day) and Milin (the 124th day) were obviously earlier than those in Lazi (the 164th day) and Rikaze (the 167th day).

The southeastern part of the TP is restricted by the Hengduan Mountains, and the water vapour transportation is limited. The area west of the Hengduan Mountains is mainly affected by the Indian summer monsoon. The humid airflow released heat and caused precipitation when climbing the windward slope, causing the atmosphere in the central region of the Hengduan Mountains to have a higher temperature but low humidity, which is a unique regional geographical phenomenon-a dry, hot valley. Thus, the rainy day onsets in the central Hengduan Mountains, e.g., Mangkang (the 150th day), Batang (the 146th day) and Derong (the 163rd day), were significantly later than those in the western Hengduan Mountains, e.g., Chayu (the 78th day) and Bomi (the 86th day).

\subsection{The Multiyear Trend of the Rainy Season Onset over the TP}

\subsubsection{Characteristics of Onset Variations in the Rainy Season on the TP}

The annual rainy season onset on the TP was calculated by all meteorological stations on the plateau (Figure 3). The year of the latest onset of the rainy season on the plateau was 1979 (the 159th day), and the year of the earliest was 2011 (the 122nd day). The results of the Theil-Sen Median trend method showed that the rainy season onset over the TP showed a relatively significant oscillating advancing trend, with an amplitude advance of $3.68 \mathrm{~d} / 10 \mathrm{a}$.

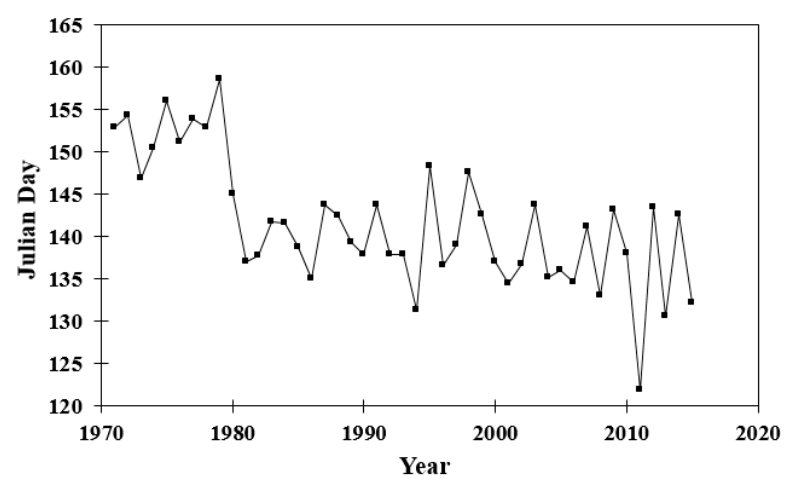

Figure 3. The trend in the rainy season onset on the TP (1971-2015). 
The trend in the rainy season onset on the plateau was expressed on a time scale: in the 1980s, the rainy season onset was significantly later than the plateau average, and there was a delayed trend; in the late 1980s, there was a large step advance in the rainy season onset, after which the trend was relatively flat and showed an early trend.

\subsubsection{Characteristics of Regional Variations in Rainy Season Onset}

On a 45-year time scale, the rainy season change trend in each climate region was similar to the overall trend on the plateau (Figure 4). The difference in the rainy season onset of each region was as follows: A. Northern Tibet (advanced $7.85 \mathrm{~d} / 10 \mathrm{a}$ ) > E. Southern Qinghai (advanced $6.76 \mathrm{~d} / 10 \mathrm{a}$ ) > D. Qaidam Basin (advanced $5.28 \mathrm{~d} / 10 \mathrm{a}$ ) $>$ K. Sichuan (advanced $5 \mathrm{~d} / 10 \mathrm{a}$ ) > B. Central Tibet (advanced 4.94 d/10 a) > C. Southern Tibet (advanced $4.1 \mathrm{~d} / 10$ a) > H. Qilian-Qinghai Lake (advanced $3.91 \mathrm{~d} / 10 \mathrm{a}$ ) > I. Bomi-Western Sichuan (advanced $2.98 \mathrm{~d} / 10 \mathrm{a}$ ) > J. Northern Yunnan (advanced $2.81 \mathrm{~d} / 10 \mathrm{a}$ ) > F. Changdu (advanced $2.45 \mathrm{~d} / 10 \mathrm{a}$ ) > H. Dawang-Chayu (delayed $4.14 \mathrm{~d} / 10 \mathrm{a}$ ). The advancing trend of the rainy season onset in the southeastern part of the TP was lower than the average level of the TP (advanced $3.68 \mathrm{~d} / 10 \mathrm{a}$ ), while the advancing trend of the rainy season onset in the central and western parts of the TP was more obvious. The occurrence of this phenomenon has a certain relationship with the topography and circulation of the plateau. The plateau monsoon region represented by the southeastern plateau was mainly affected by the Indian summer monsoon, where the advancing trend was slight. While the other regions were controlled by westerlies, the advancing trend was significantly greater than that of the plateau overall.

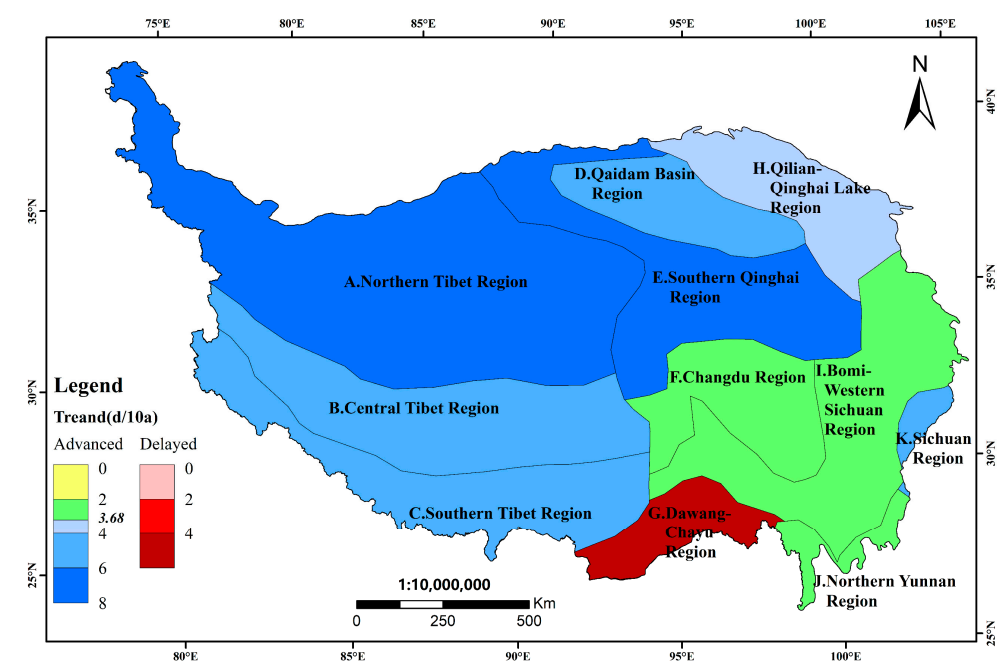

Figure 4. The differences in the trend in the rainy season onset for each region (1971-2015).

In general, the variation trend in the onset of the rainy season on the plateau was consistent with the overall trend on the plateau. The advanced trend of the rainy season onset in the southern monsoon region was moderate, but the interannual variation was more obvious. The variation in the rainy season onset in the westerly region was more obvious, but the interannual variation was slight. The more obvious variation in the monsoon circulation than in the westerlies might explain this phenomenon to some extent; however, there was a delayed trend in the monsoon circulation onset, which caused the advancing trend in the rainy season onset in the monsoon region to slow down.

\subsection{Differences in the Variations in the Rainy Season Onset before and after Mutation}

\subsubsection{Mutation Analysis}

The process in which the climate changes from one stable mode to another over a short period of time is called climate change. If the onset of the rainy season over the TP mutated over the course 
of 45 years, a key part of understanding the water cycle on the plateau is determining whether there was a difference before and after the mutation. The present study showed that there were significant differences in the rainy season onset in different regions, and the maximum difference was more than three-fold.

Annual precipitation is the most important climatic factor and represents the intuitive measure of regional precipitation. The change in precipitation in a long-term sequence is an indicator of regional climate change. Therefore, annual precipitation was used as an indicator in this paper, and the moving $t$-test model and cumulative anomaly model were used to evaluate the precipitation mutation (Figure 5).

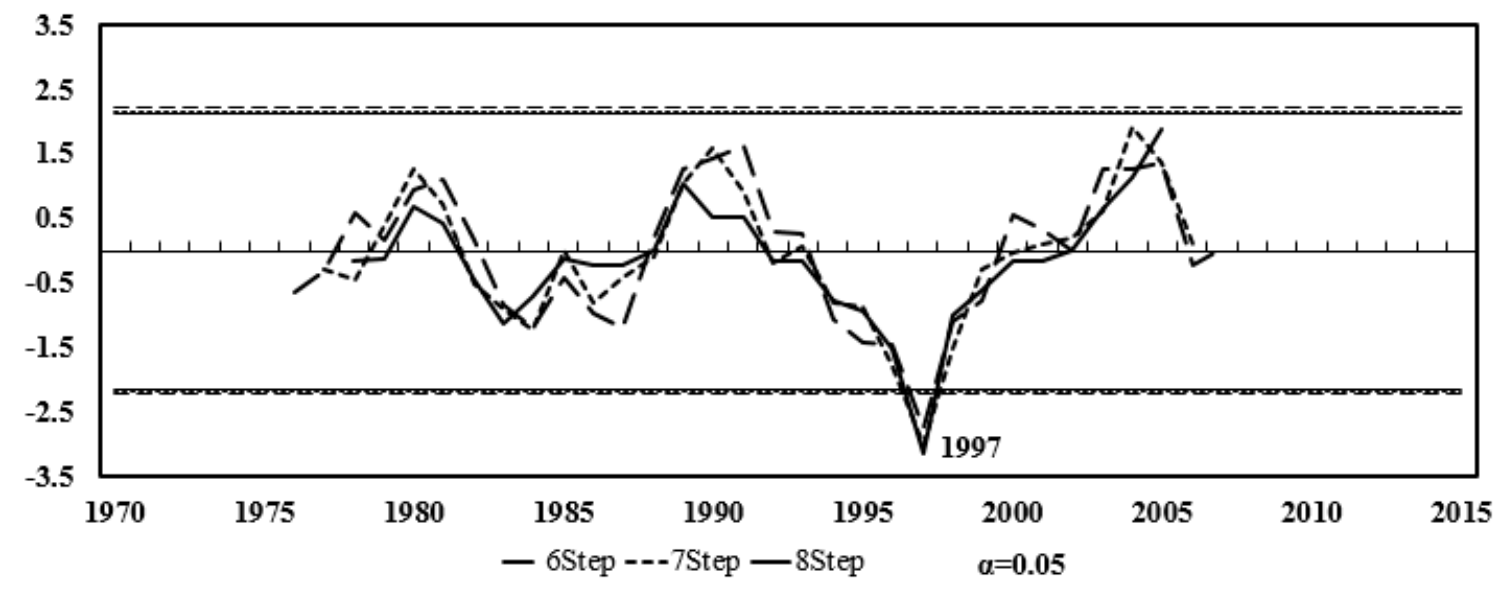

(a)

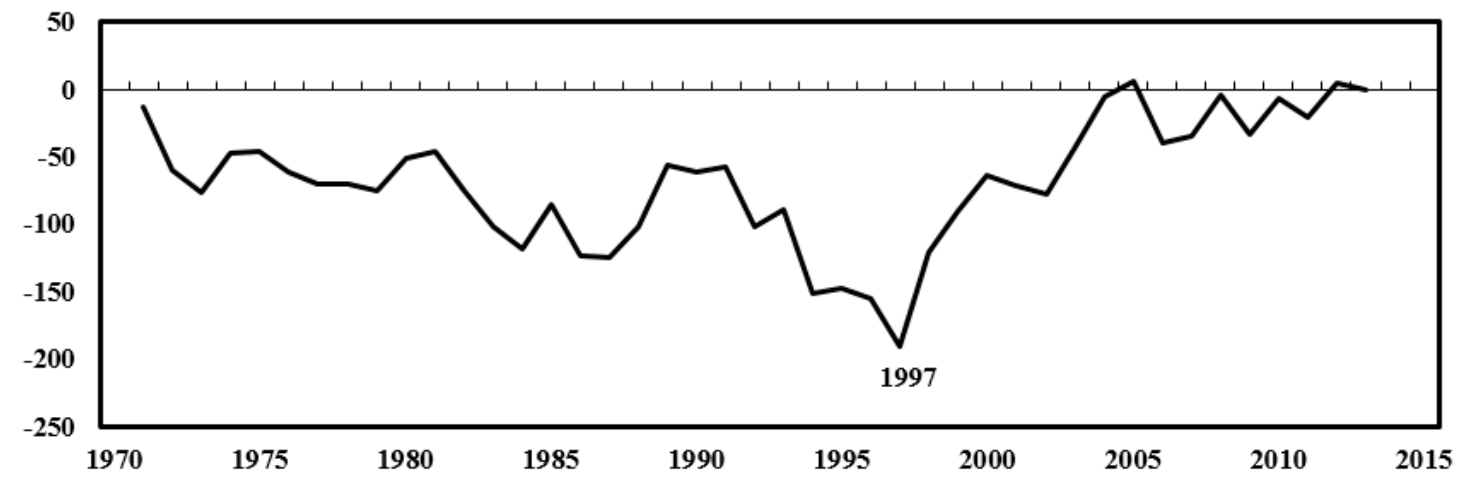

(b)

Figure 5. Mutation of the annual precipitation over the TP (a) moving $t$-test; (b) cumulative anomaly.

The results of the moving $t$-test showed that when the step size was set to 6/7/8 (i.e., $\mathrm{n}_{1}=\mathrm{n}_{2}=$ 6/7/8), the plateau precipitation was changed in 1997 and passed the 0.05 significance level test; the cumulative anomaly method showed that the cumulative anomaly of the plateau precipitation exhibited a downward trend during the period 1971-1997, reaching a minimum in 1997, while the cumulative anomaly exhibited an upward trend after 1997, which indicated that the precipitation had mutated in 1997. Therefore, 1997 could be regarded as the mutation year for precipitation and the onset of the rainy season on the TP. In the fields of marine science and atmospheric science, 1997 is also considered an important year of mutation. In marine science, 1997 is regarded as a year of abrupt change in the upper ocean temperature in the north-central Pacific [38]. With respect to the El Niño [39], the El Niño event in 1997 is considered to have been the strongest in the past 100 years and to have substantially changed the rainfall pattern in the eastern Pacific. Research on decadal changes in 
East Asian summer monsoon circulation also revealed that the monsoon underwent an abrupt change in the mid-1990s [40].

\subsubsection{Differences in the Regional Variations in the Rainy Season Onset before and after Mutation}

The differences in the rainy season onset over the TP before and after mutation were analysed with the Theil-Sen Median method (Table 2). Before the mutation, the trend in the rainy season onset at most meteorological stations over the TP was advancing (70.1\%); $62.3 \%$ of stations exhibiting an advancing trend showed a significant trend, and the stations with a delaying trend mainly appeared in the Brahmaputra Valley of the southern Tibet region and the eastern Bomi-Western Sichuan region. After the precipitation mutation on the plateau, the trend in the rainy season onset on the plateau changed significantly; the stations with an advancing trend decreased to $50.5 \%$, and only $18.8 \%$ of the stations showed an advancing trend. The proportions of stations with a delaying trend and unchanged stations increased significantly, which indicated that the trends at some stations had changed from the advanced mode to the invariant or delayed mode. Most of those stations were located in the Qaidam Basin region, Qilian-Qinghai Lake region, and Bomi-Western Sichuan region.

Table 2. The differences in the regional trends in the rainy season onset before and after the mutation.

\begin{tabular}{|c|c|c|c|c|c|c|c|}
\hline \multirow{2}{*}{$\begin{array}{l}\text { Number of } \\
\text { Stations }\end{array}$} & \multirow{2}{*}{ Region } & \multicolumn{3}{|c|}{ Before the Mutation } & \multicolumn{3}{|c|}{ After the Mutation } \\
\hline & & Advanced & Unchanged & Delayed & Advanced & Unchanged & Delayed \\
\hline 5 & A. Northern Tibet & $5 / 5$ & & & $3 / 5$ & & $2 / 5$ \\
\hline 6 & B. Central Tibet & $4 / 6$ & & $2 / 6$ & $3 / 6$ & $2 / 6$ & $1 / 6$ \\
\hline 18 & C. Southern Tibet & $5 / 12$ & & $7 / 12$ & $7 / 18$ & $5 / 18$ & $6 / 18$ \\
\hline 8 & D. Qaidam Basin & $5 / 6$ & & $1 / 6$ & $3 / 6$ & & $3 / 6$ \\
\hline 9 & E. Southern Qinghai & $7 / 7$ & & & $5 / 7$ & & $2 / 7$ \\
\hline 12 & F. Changdu & $4 / 8$ & $1 / 8$ & $3 / 8$ & $7 / 11$ & $3 / 11$ & $1 / 11$ \\
\hline 2 & G. Dawang-Chayu & $1 / 1$ & & & $1 / 2$ & & $1 / 2$ \\
\hline 12 & H. Qilian-Qinghai Lake & $10 / 11$ & & $1 / 11$ & $6 / 11$ & $1 / 11$ & $4 / 11$ \\
\hline 31 & I. Bomi-Western Sichuan & $18 / 27$ & $1 / 27$ & $8 / 27$ & $11 / 26$ & $3 / 26$ & $12 / 26$ \\
\hline 2 & J. Northern Yunnan & $2 / 2$ & & & $1 / 2$ & & $1 / 2$ \\
\hline 1 & K. Sichuan & & & $1 / 1$ & $1 / 1$ & & \\
\hline 106 & Total & $61 / 86$ & $2 / 86$ & $23 / 86$ & $48 / 95$ & $14 / 95$ & $33 / 95$ \\
\hline
\end{tabular}

\subsubsection{Differences in the Station Variations in the Rainy Season Onset before and after Mutation}

According to the mutation test results, the study period was divided into two parts (before the mutation and after the mutation), and the trend in the rainy season onset for each station was also different before and after the mutation (Figure 6). Before the plateau precipitation mutation, the trend in the rainy season onset over most of the plateau was advanced and mainly located in the $\mathrm{A} / \mathrm{B} / \mathrm{D} / \mathrm{E} / \mathrm{F} / \mathrm{H} / \mathrm{I}$ region. Almost all of the stations were located in the plateau hinterland, while the stations in the southeastern part of the plateau (east of $\mathrm{F}$ region, central I region, and $\mathrm{K}$ region) and southwest of the plateau (C region) showed a delayed trend. The spatial and temporal variations in the trend in the rainy season onset had changed significantly after the mutation. The proportions and difference between advanced stations and delayed stations were reduced (before mutation: $70.93 \%$ and $26.74 \%$, respectively; after mutation: $50.53 \%$ and $34.74 \%$, respectively), while most of the stations at the edge of the plateau showed a delayed trend. The stations in the southwestern part of the TP (C region) still showed a delayed trend; most stations in the southeastern, eastern and northeastern parts of the TP showed delayed trends, and only four stations (I region) showed an unchanged trend. 


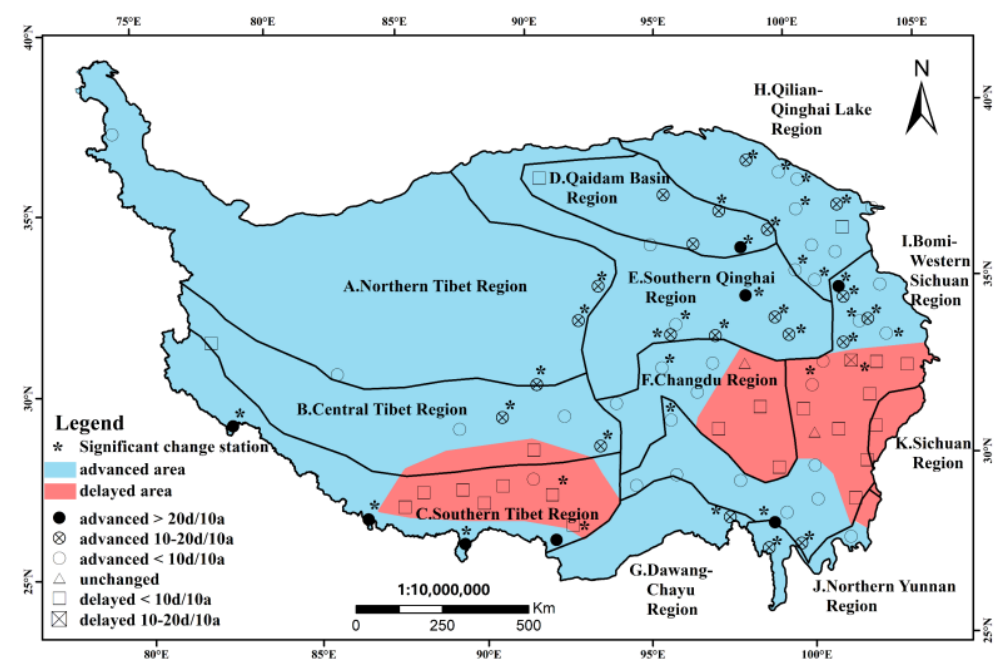

(a)

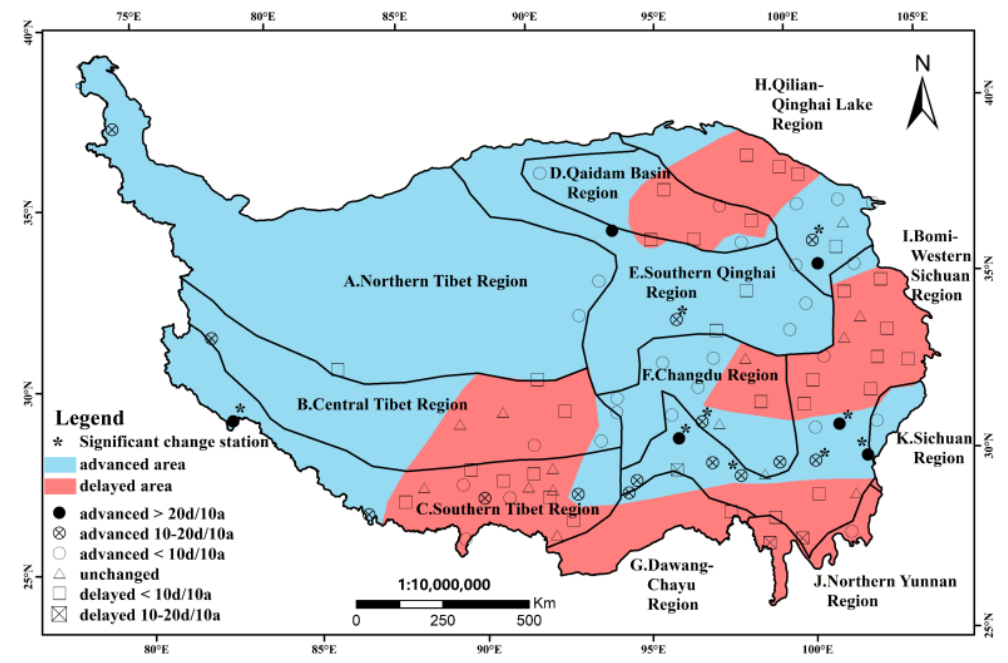

(b)

Figure 6. The differences in the trend in the rainy season onset for each station (a) before mutation; (b) after mutation.

Whether before or after mutation, the delayed stations were mostly at the edge of the TP; there was some spatial overlap, but differences remained. After the mutation, the proportion of delayed stations increased, and stations in the southern TP were located in the upper reaches of the Brahmaputra River (C region). However, after the mutation, the area of delayed onset expanded to the Central Tibet region (B region) and eastward to the southern Hengduan Mountains (J region and $\mathrm{K}$ region). The delayed stations in the area east of the TP were mainly located in the area north of the Hengduan Mountains (I region) before the mutation; however, the delayed centre underwent a significant northward trend after the mutation. In addition, after the mutation, a new delayed centre appeared in the area northeast of the TP (D region and $\mathrm{H}$ region), and the station trends in this region changed significantly from advanced (10-20 d/10 a) to delayed (within $10 \mathrm{~d} / 10 \mathrm{a}$ ).

\section{Discussion}

The global and regional atmospheric circulation was changed by climatic warming, resulting in significant changes in the temporal and spatial patterns of climatic factors, such as the rainy season and precipitation on the plateau. The plateau climate was mainly controlled by westerlies and the South 
Asian monsoon, changes in the strength of which could directly lead to changes in climatic factors. The southern and southeastern parts of the TP are mainly controlled by the South Asian monsoon, the northern and central parts of the plateau are mainly affected by westerlies, and the eastern margin of the plateau is affected by the East Asian monsoon. In April, all of the water vapour on the TP mainly originated from the zonal transportation of westerlies. With the onset of summer, the influence of the South Asian monsoon expanded from south to north, and a large amount of water vapour from the Indian Ocean and Bay of Bengal entered the plateau from the main water vapour channel of the plateau. During the main rainy season on the plateau, the precipitation in most of the southeastern and southwestern regions was regulated by the South Asian monsoon, and the northern part was still controlled by westerlies.

\subsection{The Trend in the Rainy Season Onset of the Main Plateau was Advanced}

Whether before or after mutation, the rainy season onset in most regions of the TP showed an advancing trend. Before mutation, the region of advanced onset over the plateau was mainly located in the central and northern parts of the plateau (north of $30^{\circ} \mathrm{N}$ ) and the southern part of the Hengduan Mountains, which is in the southeastern part of the plateau. After the mutation, the trend in the rainy season onset was still advanced over most of the plateau, but the area was significantly reduced, mainly in regions $\mathrm{E}, \mathrm{F}$, and $\mathrm{I}$.

The trend in the rainy season onset was mainly related to the type of atmospheric circulation and its interannual variation on different parts of the plateau. The main mountain ranges in the central and northern parts of the plateau are east-west oriented. In the area north of the Gangdese Mountains and Nyainqentanglha Mountains, the main water vapour channel for the westerlies was precipitation and the rainy season, which were both related to the strength of the westerlies. The Brahmaputra Valley was the main channel for the Indian summer monsoon, and in this region, the rainy season onset was related to the strength of the Indian summer monsoon.

In addition, the abundant precipitation carried by westerlies in the winter was blocked by the mountains on the southwestern margin of the plateau. Therefore, an obvious precipitation peak appeared in these areas from January to April, which can explain the phenomenon in which the rainy season onset in Pulan (the 78th day) and Nielamu (the 73rd day) was significantly earlier than in other regions of the plateau.

\subsection{The Trend in the Rainy Season Onset was Delayed in Some Regions over the TP}

Though the advancing trend in the rainy season onset was apparent over the plateau, several concentrated stations showed a delayed trend. Before the mutation, the concentrated stations appeared in two different regions: One was in the southern part of the TP (C region), which was mainly distributed in the Brahmaputra Valley, where the precipitation is mainly affected by the South Asian monsoon, and the second was located at the northern end of the Hengduan Mountains and south of Bayan Hara Mountain (I region and F region), which was the boundary of the zone affected by the monsoon. After the mutation, the number of delayed regions increased to three. Among these regions, the delayed region in the Brahmaputra Valley extended northward, reaching the area north of the $\mathrm{B}$ region, and the delayed region also extended eastward to the southeastern margin of the plateau. The spatial variation characteristics of the delayed region in the Hengduan Mountains showed meridional and northward extensions (covering the central and northern area of the I region). In addition, in the northeastern part of the TP, a new region of delayed onset appeared (D region and $\mathrm{H}$ region), and the trend in this region was advanced before mutation but delayed after the mutation.

\subsubsection{The Delayed Region South of Tibet}

Before the mutation, the region of delayed onset in the southern part of Tibet was mainly located in the valley region of the middle reaches of the Brahmaputra (i.e., south of the Gangdese Mountains-Nyinqing Tanggula Mountains and north of the Himalayas). The annual precipitation 
in this region was between $250 \mathrm{~mm}$ and $450 \mathrm{~mm}$, contributing to a semiarid and semihumid region. However, after the mutation occurred, the delayed region expanded across all of southern Tibet.

Before mutation, the delayed region in the Brahmaputra Valley was mainly related to the geographical location. The region was located between the two large east-west-oriented mountains on the TP, and the valley south of the plateau serves as the largest water vapour channel of the South Asian monsoon. The South Asian monsoon moves along the Brahmaputra, bringing abundant precipitation to the interior of the plateau. The southerly wind can carry water vapour to approximately the $30^{\circ} \mathrm{N}$ region on the TP, which was the centre of the delayed region. The delayed region was located at the end of the South Asian monsoon water vapour channel, and the atmospheric precipitation in this area was lacking, which led to the trend in which the onset of the rainy season differed in this region from that in other regions on the TP.

After the mutation, the delayed region had obviously extended south of the TP. The boundary of the extension region reached the B region in the north and the Hengduan Mountains in the east, including the $\mathrm{G}$ region and the area south of the I region. The expansion of the delayed region after the mutation was mainly related to the weakening of the Indian summer monsoon, which led the annual precipitation in this region to drop sharply, and the maximum decrease was up to $20 \mathrm{~mm} /$ year. Therefore, the main reason for the expansion of the delayed region south of the TP was that under the overall pattern of the weakening Indian summer monsoon, the water vapour carried by the monsoon was reduced, resulting in a decrease in the atmospheric precipitation in the region, which directly led to a delayed trend in those regions.

\subsubsection{The Delayed Region in the Hengduan Mountains}

Another region of delayed onset was concentrated in the I region. Before the mutation, the delayed region was mainly located north of the Hengduan Mountains and south of the Bayan Hara Mountains, which represented the northern boundary of the monsoon region. The delayed region tended to move northward and was located north of the Hengduan Mountains, which was mainly affected by westerlies.

Before the mutation, the rainy season in the delayed region began during summer, and the precipitation during this period was related to the geographical location and monsoon circulation. In the global atmospheric circulation pattern, the Hengduan Mountains served as the natural boundary between the East Asian monsoon and the South Asian monsoon (Indian summer monsoon), and the climate was affected by both the East Asian monsoon and the South Asian monsoon. The Indian summer monsoon has been weakening in recent decades. The river canyon between the Hengduan Mountains acted as a water vapour transport channel, but the shape of the mountains results in a complex folding of this channel (like a tie), which could block and restrain the transport of water vapour to the north. Therefore, at the end of the water vapour channel in the Hengduan Mountains, the precipitation was less abundant than in the southern part, and the onset of the rainy season showed a delayed trend.

After the mutation, the centre of the delayed region was obviously northward and mainly located to the east of the TP, which was at the end of the westerlies and monsoon. After 1998, the precipitation in this region decreased significantly, the annual onset of the rainy season in this region was on the 128th day, and the precipitation from March to May had a decrease of 0 to $5 \mathrm{~mm} / \mathrm{a}$ [16], which suggested that the reduction in precipitation during the early rainy season may be an important reason for the delayed trend in the rainy season in the region.

\subsubsection{The Delayed Region Northeast of the TP}

The third delayed region was located in the Qaidam Basin and its northeastern part (D region and part of the $\mathrm{H}$ region); the annual precipitation in this region was lower than that in any other region, and the climate was dry. The rainy season onset was in June, which was later than that on the TP. 
The change in the rainy season onset in this region from before to after the mutation was clear. Before the mutation, the rainy season onset in the region showed an advancing trend, and the advance range was 10 to $20 \mathrm{~d} / 10 \mathrm{a}$. However, after the mutation, the rainy season onset showed a delaying trend, and the delay was within $10 \mathrm{~d} / 10$ a. This phenomenon was mainly related to the significant reduction in regional precipitation. The annual precipitation in this area was mainly concentrated from June to September, which coincides with the rainy season onset. The precipitation showed a decreasing trend after 1998, which led to a new delayed region northeast of the TP after mutation.

\section{Conclusions}

The Theil-Sen Median trend analysis and Mann-Kendall test could provide accurate trends in the onset of the rainy season. The temporal and spatial characteristics of the rainy season onset over the TP were analysed from 1971 to 2015, and some of the conclusions are as follows:

There were obvious spatial characteristics in the rainy season onset; the onset time increased with a trend from south to north along the meridional direction and from east to west with latitude. Due to the influence of the monsoon, the rainy season onset on the southwestern edge of the TP was earlier than in other regions of the TP.

The rainy season onset experienced a significant mutation in 1997. Whether before or after mutation, the trend in the rainy season onset over the TP showed an overall advance and partial delay, but the region with a delayed onset was larger after the mutation.

Before the mutation, the delayed region was mainly located at the end of the water vapour channel (Brahmaputra Valley and Hengduan Mountains), where there was less water vapour flux. After the mutation, the area of delayed onset south of the TP expanded significantly, and the weakening Indian summer monsoon was the main reason. The delayed region east of the TP moved northward, which was related to the weakening westerlies. The new delayed region northeast of the TP was related to the decrease in precipitation.

Author Contributions: J.X. and Y.H. (Yuekai Hu) conceived the study, and all authors contributed to writing the paper.

Funding: This study was supported by the Zhejiang Provincial Natural Science Foundation of China (No. LY16D010007), the Hangzhou Science and Technology Plan Project of China (No. 20170533B01) and the National Natural Science Foundation of China (No. 41571339).

Acknowledgments: The authors are grateful to editors and anonymous reviewers for their constructive comments and suggestion, which highly improving the manuscript.

Conflicts of Interest: The authors declare no conflicts of interest.

\section{References}

1. Li, L.; Schmitt, R.W.; Ummenhofer, C.C. The role of the subtropical North Atlantic water cycle in recent US extreme precipitation events. Clim. Dyn. 2018, 50, 1291-1305. [CrossRef]

2. Tang, L.; Duan, X.; Kong, F.; Zhang, F.; Zheng, Y.; Li, Z.; Hu, S. Influences of climate change on area variation of Qinghai Lake on Qinghai-Tibetan Plateau since 1980s. Sci. Rep. 2018, 8, 3-9. [CrossRef]

3. Zhang, W.; Yi, Y.; Kimball, J.S.; Kim, Y.; Song, K. Climatic controls on spring onset of the Tibetan Plateau grasslands from 1982 to 2008. Remote Sens. 2015, 7, 16607-16622. [CrossRef]

4. Shen, M.; Tang, Y.; Chen, J.; Zhu, X.; Zheng, Y. Influences of temperature and precipitation before the growing season on spring phenology in grasslands of the central and eastern Qinghai-Tibetan Plateau. Agric. For. Meteorol. 2011, 151, 1711-1722. [CrossRef]

5. Sun, J.; Qin, X. Precipitation and temperature regulate the seasonal changes of NDVI across the Tibetan Plateau. Environ. Earth Sci. 2016, 75, 1-9. [CrossRef]

6. Yang, K.; Wu, H.; Qin, J.; Lin, C.; Tang, W.; Chen, Y. Recent climate changes over the Tibetan Plateau and their impacts on energy and water cycle: A review. Glob. Planet. Chang. 2014, 112, 79-91. [CrossRef] 
7. Ye, J.S.; Reynolds, J.F.; Sun, G.J.; Li, F.M. Impacts of increased variability in precipitation and air temperature on net primary productivity of the Tibetan Plateau: A modeling analysis. Clim. Chang. 2013, 119, 321-332. [CrossRef]

8. Bollasina, M.A.; Ming, Y.; Ramaswamy, V. Anthropogenic Aerosols and the Summer Monsoon. Science 2011, 334, 502-505. [CrossRef]

9. Duan, K.; Yao, T.; Thompson, L.G. Response of monsoon precipitation in the Himalayas to global warming. J. Geophys. Res. Atmos. 2006, 111, 1-8. [CrossRef]

10. Manabe, S.; Terpstra, T.B. The effect of moutains on the general circulation of the Atmosphere as Identified by Numerical Experiments. J. Atmos. Sci. 1974, 31, 3-42. [CrossRef]

11. Roxy, M.K.; Ritika, K.; Terray, P.; Murtugudde, R.; Ashok, K.; Goswami, B.N. Drying of Indian subcontinent by rapid Indian ocean warming and a weakening land-sea thermal gradient. Nat. Commun. 2015, 6, 7423. [CrossRef]

12. Wu, B. Weakening of Indian summer monsoon in recent decades. Adv. Atmos. Sci. 2005, 22, 21-29. [CrossRef]

13. Liu, X.; Chen, B. Climatic warming in the Tibetan Plateau during recent decades. Int. J. Climatol. 2000, 20, 1729-1742. [CrossRef]

14. Liu, X.; Kutzbach, J.E.; Liu, Z.; An, Z.; Li, L. The Tibetan Plateau as amplifier of orbital-scale variability of the East Asian monsoon. Geophys. Res. Lett. 2003, 30,1-4. [CrossRef]

15. Pan, B.; Li, J. Qinghai-Tibetan Plateau: A Driver and Amplifier of the global climatic change. J. Lanzhou Univ. (Nat. Sci.) 1996, 32, 108-115.

16. Ma, Z.; Xu, Y.; Peng, J.; Chen, Q.; Wan, D.; He, K.; Li, H. Spatial and temporal precipitation patterns characterized by TRMM TMPA over the Qinghai-Tibetan plateau and surroundings. Int. J. Remote Sens. 2018, 39, 3891-3907. [CrossRef]

17. Zhang, K.; Pan, S.; Cao, L.; Wang, Y.; Zhao, Y.; Zhang, W. Spatial distribution and temporal trends in precipitation extremes over the Hengduan Mountains region, China, from 1961 to 2012. Quat. Int. 2014, 349, 346-356. [CrossRef]

18. Shi, Y.; Song, L. Spatial Downscaling of Monthly TRMM Precipitation Based on EVI and Other Geospatial Variables Over the Tibetan Plateau From 2001 to 2012. Mt. Res. Dev. 2015, 35, 180-194. [CrossRef]

19. An, Z.; Kutzbach, J.E.; Prell, W.L.; Porter, S.C. Evolution of Asian monsoons an phased uplift of the Himalaya-Tibetan Plateau since Late Miocene times. Nature 2001, 411, 62-66. [CrossRef]

20. Yao, T.; Thompson, L.; Yang, W.; Yu, W.; Gao, Y.; Guo, X.; Joswiak, D. Different glacier status with atmospheric circulations in Tibetan Plateau and surroundings. Nat. Clim. Chang. 2012, 2, 663-667. [CrossRef]

21. Li, L.; Yang, S.; Wang, Z.; Zhu, X.; Tang, H. Evidence of Warming and Wetting Climate over the Qinghai-Tibet Plateau. Arct. Antarct Alp. Res. 2010, 42, 449-457. [CrossRef]

22. Zhou, S.; Wu, P.; Wang, C.; Han, J. Spatial distribution of atmospheric water vapour and its relationship with precipitation in summer over the Tibetan Plateau. J. Geogr. Sci. 2012, 22, 795-809. [CrossRef]

23. National Meteorological Information Center of China. Available online: https://earthexplorer.usgs.gov (accessed on 20 September 2019).

24. United States Geological Survey. Available online: http://data.cma.cn/data/cdcdetail/dataCode/SURF_CLI_ CHN_MUL_DAY_V3.0.html (accessed on 20 September 2019).

25. Fan, H.; Hu, J.; He, D. Trends in precipitation over the low latitude highlands of Yunnan, China. J. Geogr. Sci. 2013, 23, 1107-1122. [CrossRef]

26. Thomas, A. The onset of the rainy season in Yunnan province, PR China and its significance for agricultural operations. Int. J. Biometeorol. 1993, 37, 170-176. [CrossRef]

27. Cao, L.; Pan, S. Changes in precipitation extremes over the Three-River Headwaters region, hinterland of the Tibetan Plateau, during 1960-2012. Quat. Int. 2014, 321, 105-115. [CrossRef]

28. Theil, H. A Rank-Invariant Method of Linear and Polynomial Regression Analysis, I, II, III. Nederl. Akad. Wetensch. Proc. 1950, 53, 386-392.

29. Mann, H.B. Non-Parametric Test Against Trend. Econometrica 1945, 13, 245-259. [CrossRef]

30. Kendall, M.G. A new measure of rank correlation. Biometrika. 1938, 30, 91-93. [CrossRef]

31. Shahid, S. Rainfall variability and the trends of wet and dry periods in Bangladesh. Int. J. Climatol. 2010, 30, 2299-2313. [CrossRef]

32. Yue, S.; Pilon, P.; Cavadias, G. Power of the Mann-Kendall and Spearman's rho tests for detecting monotonic trends in hydrological series. J. Hydrol. 2002, 259, 254-271. [CrossRef] 
33. Yue, S.; Wang, C.Y. The Mann-Kendall test modified by effective sample size to detect trend in serially correlated hydrological series. Water Resour. Manag. 2004, 18, 201-218. [CrossRef]

34. Hamed, K.H.; Rao, A.R. A modified Mann-Kendall trend test for autocorrelated data. J. Hydrol. 1998, 204, 182-196. [CrossRef]

35. Hamed, K.H. Trend detection in hydrologic data: The Mann-Kendall trend test under the scaling hypothesis. J. Hydrol. 2008, 349, 350-363. [CrossRef]

36. Chen, B.; Xu, X.-D.; Yang, S.; Zhang, W.-D. On the origin and destination of atmospheric moisture and air mass over the Tibetan Plateau. Theor. Appl. Climatol. 2012, 110, 423-435. [CrossRef]

37. Yu, H.; Wang, L.; Yang, R.; Yang, M.; Gao, R. Temporal and spatial variation of precipitation in the Hengduan Mountains region in China and its relationship with elevation and latitude. Atmos. Res. 2018, 213, 1-16. [CrossRef]

38. Kim, S.B.; Lee, T.; Fukumori, I. The 1997-1999 abrupt change of the upper ocean temperature in the north central Pacific. Geophys. Res. Lett. 2004, 31, 1-4. [CrossRef]

39. Li, R.; Min, Q.; Fu, Y. 1997/98 El Niño-induced changes in rainfall vertical structure in the east Pacific. J. Clim. 2011, 24, 6373-6391. [CrossRef]

40. Kwon, M.H.; Jhun, J.G.; Ha, K.J. Decadal change in east Asian summer monsoon circulation in the mid-1990s. Geophys. Res. Lett. 2007, 34, 1-6. [CrossRef]

(C) 2019 by the authors. Licensee MDPI, Basel, Switzerland. This article is an open access article distributed under the terms and conditions of the Creative Commons Attribution (CC BY) license (http://creativecommons.org/licenses/by/4.0/). 